\title{
10 A case for removing barriers to legal recognition of transgender persons in Botswana
}

\author{
Kutlwano Pearl Magashula
}

\section{Introduction}

Botswana has seen a steady rise in progressive decisions on the rights of LGBTI persons. Most markedly, in a unanimous decision poised to set the pace for juridical recognition of LGBTI rights in Africa, the Botswana High Court decriminalized same-sex sexual practices between consenting adults in private. ${ }^{1}$ The Court in Letsweletse Motshidiemang $v$ Attorney General, determined that the 'regulation of conduct deemed indecent, done in private between consenting adults, is a violation of the constitutional rights to privacy and liberty'. In another landmark ruling, the Botswana Court of Appeal affirmed the constitutional rights of LGBTI persons to assembly, association and expression and asserted that equal protection of the law extended to everyone without distinction. Similarly, in ND v Attorney General (the Gender marker case), the High Court found that a refusal by the Registrar of National Registration to change the gender marker on a transgender (trans) applicant's identity document had interfered with his constitutional rights. This was a momentous decision that allowed trans people to alter their official identity documents to align them with their experiences of gender (legal gender recognition).

It remains apparent however, that progressive judgements alone, outside the backing of a comprehensive legislative or policy framework, are inadequate for the protection of rights. Moreover, approaches that fail to consider the lived experiences of the wider community beyond individual applicants can add barriers to the realization of rights. In the Gender marker case for example, based on the applicants' circumstances, the Court made gender-affirming surgery and hormonal therapy prerequisites for legal gender recognition notwithstanding the restricted access to such services within the Botswana public health management system. This effectively excludes self-identified trans people who have not transitioned medically from legal recognition.

This chapter explores the implication of the Gender marker case on the lives of trans persons in Botswana. It proposes more inclusive approaches to legal gender recognition that safeguard plurality and diversity. The chapter considers the different discursive models on trans identities, including the historical conceptions of gender diversity in Africa broadly and in Botswana. It critically

DOI: $10.4324 / 9781003175049-10$ 
analyzes the Gender marker case unpacking the inherent biases in the Court's approach. The case is evaluated using identity-based critiques of dominant cultural practices to show how it reinforced exclusionary norms.

\section{Part I: Understanding trans identities}

While it is common to assume that being trans involves some kind of medical procedure or treatment, many trans people either cannot afford to transition medically or opt not to. ${ }^{2}$ Furthermore, access to appropriate and adequate hormone therapy and surgery in Africa is often difficult. A 2015 report by the World Health Organization (WHO) indicates that there are still very few appropriate and accessible health services available to trans patients. ${ }^{3}$ This is often due to a lack of professional training and relevant health system standards. For trans people who wish to transition medically, the lack of access to genderaffirming services can contribute to feelings of dysphoria. As a result, some trans persons reportedly self-administer hormones obtained through illicit sources without medical supervision or guidance. ${ }^{4}$ This can result in a myriad of health complications and contribute to poor mental health and increased exposure to sexual risk. ${ }^{5}$ In a context where medical transition is a requirement for legal gender recognition, the lack of access to gender affirming treatment can present an insurmountable barrier.

Trans activists advocate that there should not be any qualifications placed on the term 'transgender' based on the ability to pass for another gender or societal standards of appearance, hormone levels or the state of one's genitals. ${ }^{6}$ This is an important assertion as such qualification results in the erasure of the distinctiveness of the community. However, many people, including mental health professionals, still view the society as a strict binary composed of biological men and women. This is presented through the strict socio-political classification of gender as either male or female. This gender essentialist approach leaves little room for gender fluidity or for non-conformity and can result in precarious legal statuses for individuals who have not undergone any physical alterations resulting in institutional discrimination.

\subsection{History of the medical conceptualization of trans identities}

Many terms used to describe trans people today were virtually unknown or not in existence as recent as ten years ago. In fact, most terms widely used then are now considered outdated or offensive. Like homosexuality, the medical study of gender diversity began in earnest in the $19^{\text {th }}$ century albeit with a conflation of gender identity and sexual orientation. ${ }^{7}$ The attribution of gender variance as a psychopathology has been credited to Krafft-Ebing (1886); however, the 'surgical construction' of gender was popularized by George Jorgensten who went to Denmark as a man and returned to the United States as a trans woman in 1967. ${ }^{8}$ Many physicians and psychiatrists at the time perceived transness as a delusional condition requiring psychotherapy and reality testing. ${ }^{9}$ It was 


\section{Kutlwano Pearl Magashula}

in this cultural context that research on gender identity made its way into scientific analysis. Despite these prevailing negative framings, physicians like Harry Benjamin are credited for popularizing the term 'transsexual' as it is currently understood and for raising awareness on trans identities within the medical profession. ${ }^{10}$ Benjamin was among the first physicians to experiment with hormonal and surgical therapy for the treatment of individuals with gender dysphoria. ${ }^{11}$

Modern medicine and psychology remain at the forefront of investigation on trans identities and medical experts continue to shape perceptions on gender diversity. ${ }^{12}$ This stems from the conception of medicine as authoritative, thorough and objective although historically, medicine has been manipulated to perpetuate oppression such as justifying slavery. Similarly, influences of oppositional sexism and essentialist assumptions about the connection between sex and gender continue to be evident in medical discourses about gender identity. ${ }^{13}$ The pathologization of trans experiences still plays a role in reinforcing gender hierarchies and disparities between normative genders and non-normative identities. ${ }^{14}$ Trans people throughout the world continue to have their access to basic human rights curtailed or denied on that basis. ${ }^{15}$ While some physicians have demonstrated a commitment to creating a safer, more inclusive world for non-normative identities, others have served to erase them. ${ }^{16}$ The legacy of these latter experts has resulted in the perception of trans experiences as abnormalities and psycho-pathologies. ${ }^{17}$ They are responsible for the slow change in attitudes about gender and invalidating the authenticity of gender-variant identities. While it has been argued that the medical model has facilitated access to health care services for trans persons, there are many issues that attach to the diagnoses of trans identities as mental disorders.

Trans people were first pathologized by the WHO through its International Statistical Classification of Diseases and Related Health Problems manual (ICD-9) in 1975. This is a manual used by clinicians and researchers globally to diagnose and categorize mental disorders. It is one of the key instruments that influenced views about trans persons along with the Diagnostic and Statistical Manual of Mental Disorders (DSM-III of 1980), published by the American Psychiatric Association. Both these manuals classified 'transgenderism' as a medical condition and mental disorder that could be treated through counselling, hormonal therapy, gender reassignment surgery and social and legal transition. The various editions of the DSM since DSM-III have approached gender diversity from the view that a discrepancy between the assigned sex (physical sex) and the psychological sex or gender, signal a psychiatric disorder. ${ }^{18}$

The diagnosis of 'gender identity disorder' in the DSM was maintained until May 2019 when it was reclassified as 'gender incongruence' and categorized as 'gender dysphoria' in DSM-V. The replacement of the diagnostic name was done with the aim of reducing stigma against trans people whilst ensuring clinical care to persons who feel they are a different gender to their assigned sex. ${ }^{19}$ Prior to its adoption, a Work Group on Sexual and Gender Identity Disorders was convened to consider revising the diagnoses. The Work Group declined to 
do so stating that this would jeopardize access to health care.$^{20}$ It however, recommended the abandonment of binary terms such as 'opposite sex' and 'anatomic sex' in the definitions of gender incongruence and replacing them with terms like 'experienced gender' and 'assigned sex. ${ }^{21}$ A similar working group was set up by the WHO in the development of ICD-11 (Working Group on Sexual Disorders and Behaviours). The working group received recommendations from civil society organizations, activists and governments of member states to remove gender diversity from its classification of mental disorders. Criticisms levelled against the continued pyscho-pathologization of trans identities centred on the stigmatization that accompanies being labelled as mentally ill in most cultures. ${ }^{22}$ The working group acknowledged that there is substantial evidence of the link between stigmatization and the classification, contributing to challenges with acquiring legal recognition, human rights abuses and restricted access to healthcare. ${ }^{23}$ Nonetheless, they too recommended retaining gender incongruence in ICD-11 to safeguard access to health. ${ }^{24}$ The principal difference between the two expert groups was that the WHO working group recommended removing gender dysphoria from categorization as a mental and behavioural disorder to 'conditions related to sexual health' whilst the DSM work group retained it as a mental condition. Whilst still pathologizing, the recommendations of the WHO working group are arguably more progressive and responsive to the needs and experiences of trans persons. The reclassification of gender dysphoria as a sexual health issue rather than a mental illness is demonstrative of a growing sensitivity to gender diversity. Nonetheless, the failure to de-pathologize demonstrates a resistance to the full acceptance of gender variant experiences. Retaining such classification is not only stigmatizing, it makes trans people objects of science rather than autonomous subjects. This places medical practitioners as paternalistic gatekeepers of legal gender recognition.

\subsection{Trans identities in Africa}

African cultures throughout the continent have a history of recognizing and accepting gender non-conformity, or at the most remaining apathetic. ${ }^{25}$ Although varying in degrees of acceptance, 'gender crossing' was common in communities like the Nigerian Hausa bori cult, the Maale of Southern Ethiopia and the Swahili speakers on the coast of Kenya. ${ }^{26}$ With the advent of colonialism and the formulation of 'African sexualities as primitive and backwards and in need of taming and civilizing', ${ }^{27}$ attitudes grew steadily repressive. Now riddled with transphobia, stemming from a context which criminalizes samesex behaviour between consenting adults, attitudes towards the trans community are more hostile. ${ }^{28}$ Across Africa, trans people face prevalent stigma and discrimination every other day, including at work, at home and using public facilities. ${ }^{29}$ In addition, they are continuously exposed to the threat of violence. Trans people are often required to disclose intimate and personal details to access routine services, violating their privacy and dignity. Moreover, having 
a gender identity that is not reflected in official identity documents effectively denies trans people rights to citizenship. ${ }^{30}$

The degree of recognition of trans individuals in Africa varies from country to country, with countries like Sudan and Mauritania being the most repressive and South Africa the most progressive. ${ }^{31}$ Although many of the laws used are meant to punish homosexuals, they invariably affect trans people because of the common conflation of gender identity and sexual orientation. South Africa remains the only country in Africa with express legislation that recognizes and protects trans persons. The Alteration of Sex Description and Sex Status Act of South Africa (ASDSS Act) was enacted to enable trans and intersex persons undergoing gender-affirming treatment to change the names and gender-markers on their identity documents. The only other African country that has expressly affirmed the right to legal gender recognition for trans people is Kenya. In Republic $v$ Kenya National Examinations Council, the Kenya High Court issued an order compelling the Kenya National Examinations Council to recall the certificate of a trans applicant and issue her with a new one bearing her preferred name and devoid of a gender marker.

\subsection{Trans identities in Botswana}

Like other African countries, the absence of a legal framework for the recognition and protection of sexual minorities in Botswana has exacerbated social exclusion, stigma in social institutions and the denial of rights. ${ }^{32} \mathrm{~A}$ research report on the mental health and wellbeing of LGBTI people in East and Southern Africa, shows that trans people in Botswana experience violence more often than the general population. ${ }^{33}$ Similarly, experiences of sexual violence are significantly higher among trans and gender non-conforming people than with other sexual minorities. ${ }^{34}$ Although there is no law in Botswana which makes it illegal to identify as homosexual and indeed trans, and despite clarifications to this effect by the High Court, trans people continually face harassment and are subjected to arbitrary arrest and detention. ${ }^{35}$ Public officials have been known to use laws such as the Penal Code, which contains provisions which criminalize same-sex sexual practices, to harass individuals. In addition, police have been known to charge trans persons under offences relating to nuisance, idle and disorderly conduct and vagrancy, especially those who are also sex workers. In 2019, however, the Botswana High Court declared sections 164 and 165 of the Penal Code ultra vires the Constitution as they violate rights to privacy and liberty. The Attorney General has filed an appeal on the basis that the High Court exceeded its jurisdiction by overruling the decision of the Court of Appeal in Kanane $v$ the State which fortified the notion that Batswana are not ready to embrace homosexuality.

The Rainbow Identity Association of Botswana (RIA), an organization that advocates for the recognition and inclusion of trans and intersex persons in Botswana, has noted some of the challenges faced by trans persons in obtaining documents reflecting their gender identity. In a contribution to a 
stakeholder report submitted to the second cycle of the Universal Periodic Review of Botswana, RIA noted that the procedure for legal gender recognition is unsystematic and unclear. ${ }^{36}$ It criticized the requirement on applicants to submit to courts, medical reports concerning their gender identity without the benefit of the cooperation of the Ministry of Health. ${ }^{37}$ In addition, Botswana does not offer gender affirming surgery as part of national health services. Hormone therapy is available at government hospitals but given at the discretion of medical practitioners who often display transphobic attitudes and consider being trans a lifestyle choice rather than an inherent part of identity. ${ }^{38}$

\section{Part II: A critical analysis of the case}

The Court in the Gender marker case was seized with a challenge by a trans man, against the refusal to alter the gender marker on his national identity document (omang) to reflect his self-identified gender. The applicant who had been diagnosed with gender identity disorder (gender dysphoria), had undergone hormonal therapy and gender affirming surgery to make his body congruent with his gender identity. These procedures altered his physical and outward appearance and gave him a masculine appearance. Because of the divergence in the information contained in his omang and his physical appearance, the applicant applied to have his gender marker altered. The request was denied on the basis that sex assigned at birth determines the contents of one's omang. The applicant then lodged an application with the High Court arguing that the refusal violated his constitutional rights to equal protection of the law, right to freedom from inhuman and degrading treatment, right to privacy, right to freedom of expression and the right to protection from discrimination. The Registrar of National Registration (Registrar) argued that his wide-ranging discretion was limited in this case as Botswana employed a system where sex was determined at birth. He argued that identity documents issued by the state reflect sex and not gender identity and that the applicant sought to change his sex and not gender. He argued further, that there was no conclusive medical or legal position that could determine when a person's sex has changed. The Registrar argued that the law did not make provision for such changes and in the absence of an enabling statute the change could not be allowed. He insisted that the decision to undergo gender re-orientation was that of the applicant and as result no state responsibility arose. On violation of rights, he stated that by denying the application, he was in fact, upholding the applicant's right to equal treatment and freedom from discrimination as he does not register and change particulars based on individual desires alone or coupled 'with an unproven medical or legal threshold as to what constitutes a change in particulars'.

In response to the Registrar's submissions, the Court observed that an exercise of discretion should consider all the relevant circumstances to make a decision that is reasonable and justifiable. Relevant circumstances were said to 
include the medical evidence presented plus the recommendations made by physicians that the gender marker should be altered to align it with his male identity. The Court noted that the National Registration Act (the Act), which allows for changes in particulars, does not state whether the changes to a person's particulars should be involuntary or can be 'self-inflicted'. Rejecting the argument that the absence of a law on legal gender recognition meant that the change could not be made, the Court cited comparative case law which establishes that in the absence of legislative guidance, courts must take into account medical evidence establishing the gender of the applicant. The Court found that the state has a duty to uphold the fundamental rights of every person and to promote tolerance, acceptance and diversity within a constitutional democracy. It found that this includes taking all necessary legislative, administrative and other measures to ensure that procedures exist for all state-issued identity documents which reflect a person's gender or sex to reflect their self-defined gender. It found that having an identity document that correctly reflects selfidentified gender is fundamental to the right to dignity and freedom of expression. The Court expressed that by permitting changes to gender markers, the Registrar would be giving effect to the spirit and purport of the Constitution and extending much-needed help to vulnerable trans persons. It found that non-recognition of the applicant's gender identity denied him equal protection of the law, thereby leaving him extremely vulnerable to harassment and violence in both public and private spheres. It observed that this can result in extreme discrimination in all societal spaces, especially in the areas of employment, education and healthcare.

\subsection{Significance of the case}

This case gave legal gender recognition to trans people in Botswana in a context rife with systematic exclusion of non-normative identities. Faced with arguments that changing the applicant's gender marker would compromise the integrity of the National Identification Register, the Court stayed faithful to its role in the protection of rights and stated that rights could not be limited on the basis of mere conjecture and speculation. The Court applied a liberal construction of the Act, opening up its interpretation to include self-determined gender, albeit supported by medical evidence. In arriving at its decision, the Court considered the prevalent discrimination, stigma and harassment faced by trans people whose gender identity is not recognized. In this regard, the Court emphasized the state's and indeed wider society's duty to respect and uphold the individual right to dignity notwithstanding any difference in views. Furthermore, the Court took note that sex cannot always be accurately identified at birth and must be viewed in light of gender identity. Responding to the scarcity of local authorities on gender identity, the Court opened itself to guidance from jurisprudence from international comparative case law and referred to international human rights instruments and related documents. This demonstrates a growing judicial openness to the transfer of experiences, learning and development. This approach 
allowed the Court to interpret the Constitution as a living document that grows and evolves in response to the changing needs and values of society.

\subsection{Critique of the case}

A critical interrogation of the decision exposes some inherent biases which disregarded the complexity of gender identity and the diversity of the trans community. The principal critique of the case is that it had the effect of pathologizing trans people and perpetuating the perception that they suffer from mental conditions. It further created a restrictive medical criterion for legal gender recognition that disregards autonomy to self-determine gender. By placing emphasis on the applicant's physical and outward appearance and expression, the Court made the physical embodiment of, or 'passing' for the gender one identifies as, a requirement for legal gender recognition. This is a restrictive and exclusionary criterion that reinforced gender binaries and cisnormative biases which benefit those who fit into dominant ideas of what it means to be male or female while ignoring those who cannot afford gender affirming treatment or who choose not to transition medically.

The Court's approach comports with a theory advanced by Stella Nyanzi, ${ }^{39}$ who in interrogating the various theoretical approaches to governing sexuality makes reference to the model of the 'charmed circle', a sexual hierarchy concept developed by the feminist scholar, Gayle Rubin. ${ }^{40}$ This is a metaphorical tool through which identity is appraised according to a hierarchical system of sexual value influenced by religion, psychiatry, popular culture and politics. ${ }^{41}$ The position in the value metrics determines which sexual practices are rewarded with social approval and which ones are denigrated as vice. ${ }^{42}$ The 'charmed circle' comprises of 'good', 'normal' and 'natural' sexualities and the 'outer limits' include 'bad', abnormal' and 'unnatural' sexualities. ${ }^{43}$ Individuals whose behaviour ranks higher in the hierarchy, such as married heterosexual reproductive couples, are rewarded with certified mental health, respectability, legality and institutional support. ${ }^{44}$ Individuals whose sexual behaviour places them lower on the scale are subjected to a presumption of mental illness, criminality, restricted social and physical mobility and loss of institutional support. ${ }^{45}$ Although the theory has been critiqued by various scholars, Nyanzi argues that it is important because it helps understand how dominant ideologies construct, control and constrain sexualities. ${ }^{46}$ She contends that it is a useful tool for scholars of African sexualities involved in the examination of the hegemonic control of diverse sexualities by social powers such as religious, biomedical, heteronormative or patriarchal influences. It is evident that the Court in this case did not escape the influences of normative understandings of gender. As a result, it created a protected category of trans persons who by virtue of their class and 'passing' privileges are proximate to what is considered 'normal' and acceptable and are therefore rewarded with recognizability and legal gender recognition. 
This theory is similar to Charles Ngwena's contention that 'natural categories' are used to legitimize the institutional exclusion of non-heteronormative sexualities. ${ }^{47}$ Charles Ngwena calls for moving from oppressive generalizations and capturing the sexualities of Africans in their diverse social groupings and individual subjectivities. ${ }^{48}$ The overriding goal, according to Ngwena, is overcoming social or status subordination arising from sexual hierarchy-related exclusionary laws and practices. ${ }^{49}$ Status subordination is viewed as imposing a single or over-simplified group identity that ignores particularities and assumes a conformity of interests. ${ }^{50}$ Ngwena views the failure to see a multiplicity of identities or to accommodate intersectionality and struggles within social groups seeking affirmation as paradoxically rendering equality oppressive.$^{51} \mathrm{He}$ reiterates that sexuality should be understood not as sameness but as relational and non-hierarchical difference and that people must be able to articulate different needs without being required to assimilate to a normative standard. ${ }^{52}$ The failure of the Court in this case to recognize diversity in gender expression resulted in a form of status subordination that necessarily dictates that those who seek legal gender recognition must assimilate to normative standards of gender. This essentially forces trans individuals seeking recognition to conform to performative gender norms, such as dress, mannerisms and to undergo medical treatment to alter their bodies or risk losing institutional support.

A further critique of the case is that although the Court found that an absence of laws to ensure a clear process for legal gender recognition exposed the process to the exercise of unfettered discretion, it made no related orders pending enactment of the necessary legislation. With the understanding that in a constitutional democracy, courts must be wary of taking over the legislative function and not be prescriptive in their remedial orders, the Court ought to have provided some guidance, more so that this was an exercise in constitutional adjudication. The Court as the ultimate interpreter and arbiter of the Constitution had a duty to ensure that the rights of the wider trans community, were effectively protected in the absence of clear legal guidance. It has been established that the interpretation of legislation or Acts of parliament is an interpretation of the Constitution as laws are enacted to serve the public good or public interest. This is buttressed by section 26 of the Interpretation Act of Botswana, which states that "every enactment shall be deemed remedial and for the public good and shall receive fair and liberal construction as will best attain its object according to its true intent and spirit'. Accordingly, the courts are mandated to interpret the Constitution, and by extension legislation, as a living and dynamic document of progressive human rights. In this spirit, the Botswana Court of Appeal has held in Attorney General v Dow, that 'the Constitution... is meant to serve not only this generation but also generations yet unborn...the primary duty of judges is to make the Constitution grow and develop in order to meet the just demands and aspirations of an ever developing society...' The Court ought to have accorded a generous and broad interpretation of the Act which would render it inclusive of all forms of gender identity and expression. 


\section{Part III: International human rights law \& standards on legal gender recognition}

International human rights law makes provision for the right to legal gender recognition and sets standards for gender registration. The Court in the Gender marker case considered these standards however not in their entirety. The following discussion demonstrates how an extensive consideration of these standards would have benefitted the trans community in Botswana.

\subsection{The Yogyakarta Principles}

The Court referenced the Yogyakarta Principles, which are a set of 29 internationally recognized principles developed by a team of human rights experts for the protection of the rights of LGBTI persons. They state in their definition of gender identity that it 'may involve if freely chosen, modification of bodily appearance or function by medical, surgical or other means...' (emphasis added). Principle 3 explicitly states that, no one shall be forced to undergo medical procedures including sex reassignment surgery and hormonal therapy as a requirement for the legal recognition of their gender identity. In addition, the Court had regard to the supplementary Yogyakarta Principles (YP+10). Principle 31 of the YP+10 provides for the right to change gendered information in identity documents while gendered information is included. The principle calls on states to ensure that official identity documents only include personal information that is relevant, reasonable and necessary as required by the law for a legitimate purpose, thereby ending registration of sex and gender in identity documents. It further calls on states to ensure access to mechanisms to change names based on the self-determination of the applicant. Where sex and gender continue to be registered, the principle requires states to ensure access to mechanisms that legally recognize and affirm each person's self-identified gender identity, make available a multiplicity of gender marker options, and ensure that no eligibility criteria is used as a prerequisites to change information. Similarly, Principle 32 provides for the right to bodily and mental integrity, autonomy and self-determination. The YP+10 call on states to ensure access to gender affirming healthcare, provided by the public health system or if not so provided, that the costs be covered or reimbursable under private and public health insurance schemes.

Both sets of principles make express provision for the right to legal gender recognition without any eligibility criteria. They recognize that requirements for medical or psychological interventions as prerequisites to change name, legal sex or gender are unnecessary. The trans community would have benefited from a liberal application of the principles to the Gender marker case.

\subsection{The United Nations human rights framework}

UN special procedures and treaty bodies have spoken out against the pathologization of trans identities in legal gender recognition. In 2015, a selection of 
UN agencies released a joint statement calling for legal gender recognition without stringent and abusive requirements. ${ }^{53}$ The Committee on Economic, Social and Cultural Rights (Committee on ESCR), in General Comment 22, has also found that regulations requiring trans persons, to be treated as mental or psychiatric patients, or requiring that they be 'cured' or 'treated', violate rights to sexual and reproductive health. The Committee on ESCR further found that laws and policies that indirectly perpetuate coercive medical practices, including hormonal therapy and surgery or sterilization requirements for legal gender recognition, constitute violation of state responsibility to respect human rights. The UN High Commissioner for Human Rights has stressed that states must respect the physical and psychological identity of trans persons by legally recognizing self-identified gender without additional requirements that may violate rights. ${ }^{54}$ This sentiment has been echoed by various treaty bodies, in their recommendations to specific countries, including the Committee on the Elimination of all forms of Discrimination against Women which criticized Switzerland for the persistence of gender reassignment surgery targeting trans persons, including involuntary medical treatment. In 2017, the Human Rights Committee dealt with its first individual case on the right to legal gender recognition in $G v$ Australia. The Committee held that Australia's policy forcing married trans persons to divorce as a requirement for legal gender recognition violated their rights to privacy, family life as well as the right to be free from discrimination. In a later review of Australia, the Committee stated that the state should take necessary measures to remove surgery and marital status requirements for sex marker changes on official documents.

In 2017, the Independent Expert on protection against violence and discrimination based on SOGI stated that the prevalent practice of denying trans persons recognition of their self-identified gender, even with gender realignment surgery, leads to violence and discrimination..$^{55}$ In the report, the Independent Expert made an invitation to destigmatize and depathologize trans identities to ensure respect for all persons without distinction. ${ }^{56}$ Similarly, in 2019, the Independent Expert recommended that states enact gender recognition laws concerning the rights of trans persons to change their names and gender markers on identification documents. ${ }^{57} \mathrm{He}$ called on states to enact procedures that are quick, transparent and accessible, without abusive conditions and respectful to the principle of free and informed choice and that of integrity.$^{58}$ Although the 2019 report postdates the Gender marker case, it merely reinforced that requirements for surgical and hormonal treatments as prerequisites for legal gender recognition violate human rights principles. A consideration of this framework would have undoubtedly resulted in a different approach by the court in the Gender marker case.

\subsection{The African human rights system}

There is no express mention of legal gender recognition within the framework of the African human rights system. However, through the issuance 
of Resolutions, General Comments and other communications, the African Commission has affirmed the freedom from discrimination based on gender identity. Protection of trans people against violence and discrimination in Africa is anchored on two binding treaties: The African Charter on Human and Peoples' Rights (African Charter), 1981, and the Protocol to the African Charter on the Rights of Women in Africa (Maputo Protocol), 2003. The African Charter observes the rights to equality and equal protection of the law, freedom from discrimination and the rights to life, dignity and integrity. The Maputo Protocol imposes obligations on states to take specific measures to combat violence against women regardless of their sexual orientation or gender identity. In 2014, the African Commission on Human and Peoples' Rights (African Commission) adopted Resolution 275, which expresses grave concern about the increasing violence and other human rights violations against persons based on their real or perceived sexual orientation or gender identity. The Resolution urges states to take action to stop violence and ensure adequate remedies are provided to victims of violence. Building on this framework, the African Commission included in its 60th session agenda, items pertaining to sexual orientation, gender identity and sex characteristics, including 'corrective' rape to ensure protection of human rights defenders. In 2018, the African Commission held a joint dialogue with the Inter-American Commission on Human Rights and the UN human rights mechanisms on sexual orientation and gender identity. ${ }^{59}$ This was a follow up to a similarly themed dialogue held in $2015 .{ }^{60}$ The participants of the dialogue emphasized the applicability of human rights standards to LGBTI persons and highlighted states' obligation to create an enabling environment for the effective enjoyment of rights. ${ }^{61}$ The Court in the Gender marker case missed an opportunity to fully operationalize Resolution 275.

\section{Comparative jurisprudence and legislation}

Comparative case law provides guidance on approaches to legal gender recognition that are inclusive and not burdensome. For example, the Indian Supreme Court in National Legal Services Authority $v$ Union of India has found that self-determination of gender is an integral part of self-autonomy and selfexpression and falls within the realm of personal liberty. It found that self-identified gender can be either male or female or a third gender and that the rights of trans persons have to be protected irrespective of chromosomal sex, genitals, assigned birth sex or implied gender roles. The self-determination approach employed by the Court in this case demonstrates that legal gender recognition can be granted outside of restrictive medical requirements. Similarly in $1 \mathrm{Bv}$ $R$ the German Federal Constitutional Court found that the requirement in the Civil Status Act of Germany (2007), for every person's sex to be entered on the birth register, outside of the availability of a third option for intersex persons, was unconstitutional and amounted to discrimination based on sex. It further found that the requirement for every person to be registered as either 
male or female deprived those who fall outside of the binary, the opportunity to be identified in their innate gender. The judgement has been welcomed as a milestone in the protection of the rights of intersex persons, for providing for a third gender option, a radical challenge to dominant ideas of sex and gender. ${ }^{62}$ These two cases demonstrate an awareness of the unpredictability of sex and gender and that trans people are characterized by differences in gender expression and not all fit neatly into binary gender categories. An openness to gender diversity beyond traditional understandings of man and woman is critical for ensuring inclusivity and plurality.

Like case law, different countries employ differing approaches to legislation on gender recognition. While the medical approach remains prevalent, many countries have made a move towards the depathologization of gender diversity. Notably, Argentina and Malta both have model laws on legal gender recognition. The Human Rights Committee has lauded the Gender Identity Act of Argentina (2012) as a best practice for legal gender recognition. The law was celebrated for its simple administrative processes for modification of sex markers without any requirements of medical diagnosis and medical treatment. The Act does however, allow for access to gender affirming surgical interventions and hormonal treatments for those who are desirous of transitioning medically. It obligates the state to either provide or ensure access to gender affirming health care. The Act requires neither judicial interventions, nor a diagnosis with gender dysphoria, demonstrating that gender diversity can be depathologized without hampering access to gender affirming healthcare. Similarly, the Gender Identity, Gender Expression Sex Characteristics Act (GIGESC Act) of Malta (2015) encompasses both legal recognition and protection against discrimination for trans and intersex persons. This radical combination sets Malta apart from other gender identity laws. The GIGESC recognizes the right to bodily integrity and physical autonomy as an immutable part of the right to gender identity. It recognizes the right to gender identity and to be treated according to one's gender identity, including the right to be identified in that way in identity documents. Like the Argentinian Act, the Act does not require proof of medical procedures. The Act also recognizes foreign decisions on gender identity including gender markers other than male or female or no gender at all. The GIGESC Act explicitly denounces the pathologization of any form of gender identity or expression and states that the nullification of classification under the ICD or any other classification shall not impact the provision of any healthcare service related to sex or gender negatively. Other non-pathologizing gender recognition laws can be found in Colombia, Denmark, Ireland and Norway. These prove that a legal and administrative framework can be established to facilitate legal gender recognition without restrictive conditions. Borrowing from this progressive comparative legislation, Botswana can develop a framework for legal gender recognition that not only ensures that trans people are depathologized but that expressly makes provision for self-determined gender. 


\subsection{Emerging models of gender recognition}

There are other emerging models to gender recognition such as ending gender registration as envisaged by Principle 31 of the $\mathrm{YP}+10$. The principle calls for the curtailment of collection of gender and sex information where possible, considering issues of national security and other legitimate concerns. While acknowledging that data on gender and sex may be necessary for national development initiatives such as ensuring gender equity, such information can be collected without the need to include it on official identity documents. The recording and visible display of gender markers in identity document as already demonstrated, can infringe rights to privacy and the freedom from discrimination. Furthermore, in the face of technological advancements and the use of bio-metric data, the use of gender markers has grown increasingly obsolete and unnecessarily invasive. There are other means of identity verification such as the unique identification number in omang cards which ensures robustness of the national identity system and capturing of gendered data without express registration. ${ }^{63}$ Ending gender registration would be an important step towards building a society that accepts gender as personal.

Another emerging approach is the recognition of gender plurality, including the adoption of a third gender or ' $x$ ' as a viable gender marker. This ensures social and cultural participation for those who do not conform to normative conceptions of gender or who fall outside of those gender constructs. With the understanding that personal autonomy and self-determination are core to individual conceptions of gender, it follows that non-binary persons or gender non-conforming persons should be allowed to use gender markers that are representative of their gender identities. The recognition of gender plurality will of course necessitate a dismantling of conformist considerations of gender and a deliberate effort to build understanding of plurality and acceptance of difference. This is important for ensuring equality before the law as well as equal protection of the law. Jurisprudential comparisons provide an evidential basis for this assertion, especially Justice Sikri in National Legal Services Authority $v$ Union of India that equality is anchored on two complementary principles, non-discrimination and reasonable differentiation, are particularly instructive. The Judge observed that equality is not just about preventing discrimination, but about ending systematic discrimination. He emphasized that reasonable differentiation speaks to creating a gender classification that would accommodate non-binary gender experiences and bring them within the fold of rights enjoyed by traditional male and female genders. While acknowledging the administrative difficulties and uncertainties that may come with implementation of a third gender category, jurisprudential comparisons provide an in-depth evidential basis for learning and improving. ${ }^{64}$ Besides, administrative challenges cannot suffice as justification for limiting the enjoyment of rights. Other gender-inclusive models for gender recognition include the opt-in model where the gender of all new born babies on birth certificates is indicated 
with an ' $x$ ' and upon attaining the age of 16, they choose their sex descriptor. ${ }^{65}$ This model, which comports with the self-identification approach, is premised on the understanding that every form of gender identity expression is legitimate and therefore should be recognized. ${ }^{66}$

\section{Conclusion}

The Gender marker case affirmed that trans people form part of the diversity of Botswana and acknowledged that the ability to access proper identification, that is representative of one's self-determined gender, is at the core of humanity and dignity. Although not establishing a framework for administration of requests for changes in gender markers, it helped clarify that this was a constitutionally enforceable right.

The approach adopted by the Court however, created a restrictive requirement for legal gender recognition predicated upon essentialist conceptions of gender. This is notwithstanding that international human rights law calls for the repeal of discriminatory practices that hinder access to legal gender recognition. Moreover, comparative jurisprudence and legislation provide guidance on alternative approaches to legal gender recognition that are not unnecessarily burdensome and respect the rights of trans persons to self-determination.

It is important to emphasize that the recommendation for the removal of medical requirements for legal gender recognition is not to dismiss the importance of ensuring access to gender affirming services for those who are desirous of transitioning medically. This is critical for alleviating experiences of gender dysphoria and ensuring access to health. Access to gender affirming healthcare services must be facilitated for trans people who wish to transition medically. To ensure accessibility, it should be provided by the public health system or covered by private and public medical aid schemes.

\section{Notes}

1 FViljoen 'Botswana court ruling is a ray of hope for LGBT people across Africa' (2019) http://theconversation.com/botswana-court-ruling-is-a-ray-of-hope-for-lgbt-peopleacross-africa-118713 (accessed 2 September 2019).

2 J Serano Whipping girl: A transsexual woman on sexism and the scapegoating of femininity (2007) 11 at 31.

3 World Health Organization Sexual health, human rights and the law Report (2015).

4 S Winter et al 'Synergies in health and human rights: A call to action to improve transgender health' (2016) 388 The Lacet 318-321.

5 As above.

6 Serano (n 2) 11.

7 J Drescher 'Transsexualism, gender identity disorder and the DSM' (2010) 14 Journal of Gay and Lesbian Mental Health 111.

8 As above.

9 As above.

10 Harry Benjamin was an endocrinologist and sexologist known for his clinical work with trans persons. 
11 Drescher (n 7).

12 Serano (n 2) 115.

13 G Ansara 'Cisgenderism in medical settings: Challenging structural violence through collaborative partnerships' in I Rivers \& R Wards (eds) Out of the ordinary: LGBT lives (2012) 93-111.

14 As above 96.

15 J Theilen Depathologisation of transgenderism and international human rights law' (2014) 14 Human Rights Law Review 327-342.

16 Serano (n 2) 115.

17 As above 116.

18 P Cohen-Kettenis \& F Pfäflin “The DSM diagnostic criteria for gender identity disorder in adolescents and adults' (2009) 2 Archives of Sexual Behavior 499-513.

19 DSM-V Fact sheet on gender dysphoria, American Psychiatric Association (2013) https://www.psychiatry.org/psychiatrists/practice/dsm/educational-resources/dsm-5fact-sheets (accessed 20 June 2019).

20 As above.

21 As above.

22 G Reed et al 'Disorders related to sexuality and gender identity in the ICD-11: Revising the ICD-10 classification based on current scientific evidence, best clinical practices, and human rights conditions' (2017) 16 World Psychiatry Journal 209.

23 As above.

24 As above.

25 S Murray 'Africa: Sub-Saharan, pre-independence' in CJ Summers (ed) GLBTQ: An encyclopedia of gay, lesbian, bisexual, transgender and queer culture (2004) 160-163.

26 As above.

27 S Nyanzi 'Unpacking the [govern]mentality of African sexualities' in S Tamale (ed) African sexualities: $A$ reader (2011) 447.

28 G Jobson et al 'Transgender in Africa: Invisible, inaccessible, or ignored?' (2012) SAHARA Journal of Social Aspects of HIV/AIDS 160.

29 Southern Africa Litigation Centre (SALC) 'Laws and policies affecting transgender persons in Southern Africa' Booklet (2016) 1.

30 As above.

31 Sudan and Mauritania retain the death penalty for male same-sex sexual conduct.

32 L Mpelega 'Interpretation of lived experiences of transgender people in Gaborone Botswana' (2013) Master of Education research essay, University of Botswana 6.

33 A Müller et al 'Are we doing alright? Realities of violence, mental health, and access to healthcare related to sexual orientation and gender identity and expression in East and Southern Africa: Research report based on a community-led study in nine countries' (2019) 138.

34 As above.

35 SALC booklet (n 29) 21.

36 Universal Periodic Review (second cycle) Botswana Stakeholder Report 2012.

37 As above.

38 As above.

39 Nyanzi (n 27) 447.

40 G Rubin 'Thinking sex: Notes for a radical theory of the politics of sexuality' in $\mathrm{P}$ Aggleton \& R Parker (eds) Culture, society and sexuality (2006) 143-178.

41 Nyanzi (n 27) 483.

42 As above.

43 As above 484.

44 Rubin (n 40) 151.

45 As above.

46 Nyanzi (n 27) 484. 


\section{Kutlwano Pearl Magashula}

47 C Ngwena 'What is Africanness? Contesting nativism in race, culture and sexuality' (2018) 198.

48 As above 205.

49 As above 207.

50 As above 208 .

51 As above.

52 As above.

53 UN Office of the High Commissioner for Human Rights, joint UN statement on ending violence and discrimination against lesbian, gay, bisexual, transgender and intersex people (2015).

54 Report of the UN High Commissioner for Human Rights on discrimination and violence based on sexual orientation and gender identity A/HRC/29/23 (2015).

55 Report of the Independent Expert on protection against violence and discrimination based on sexual orientation and gender identity on the promotion and protection of all human rights, civil, political, economic, social, cultural rights, including the right to development A/HRC/35/36 (2017).

56 As above.

57 Report of the Independent Expert on protection against violence and discrimination based on sexual orientation and gender identity Resolution A/HRC/41/45 (2019).

58 As above.

59 Inter-American Commission on Human Rights, African Commission on Human and Peoples' Rights and United Nations human rights mechanisms 'Joint thematic dialogue on sexual orientation, gender identity and intersex related issues' (2018).

60 Centre for Human Rights 'Ending violence and other human rights violations based on sexual orientation and gender identity: A joint dialogue of the African Commission on Human and Peoples' Rights, Inter-American Commission on Human Rights and United Nations' (2016).

61 As above.

62 H Botha 'Beyond sexual binaries? The German Federal Constitutional Court and the rights of intersex people' (2018) 21 Potchefstroom Electronic Law Journal 1-26.

63 World Bank Group Identification for development (ID4D) country diagnostic: Botswana (2016) 17.

64 B Deyi 'First class constitution, second class citizen: Exploring the adoption of the thirdgender category in South Africa' in S Namwase \& A Jjuuko (eds) Protecting the human rights of sexual minorities in contemporary Africa (2017) 128.

65 As above 140.

66 As above.

\section{References}

Ansara, G 'Cisgenderism in medical settings. Challenging structural violence through collaborative partnerships' in Rivers, I and Wards, R (eds) Out of the ordinary: LGBT lives (Ashgate 2012)

Centre for Human Rights 'Ending violence and other human rights violations based on sexual orientation and gender identity: A joint dialogue of the African Commission on Human and Peoples' Rights, Inter-American Commission on Human Rights and United Nations' 2016.

Cohen-Kettenis, P \& Pfäflin, F 'The DSM diagnostic criteria for gender identity disorder in adolescents and adults' (2009) 2 Archives of Sexual Behaviour 499 
Deyi, B 'First class constitution, second class citizen: Exploring the adoption of the thirdgender category in South Africa' in Namwase, S and Jjuuko, A (eds) Protecting the human rights of sexual minorities in contemporary Africa (PULP 2017)

Drescher, J 'Transsexualism, gender identity disorder and the DSM' (2010) 14 Journal of Gay and Lesbian Mental Health 111

DSM-V Fact sheet on Gender Dysphoria, American Psychiatric Association (2013) https:// www.psychiatry.org/psychiatrists/practice/dsm/educational-resources/dsm-5-fact -sheets (accessed 20 June 2019)

Jobson, G, Theron, L, Kaggwa, J \& Kim, H 'Transgender in Africa: Invisible, inaccessible, or ignored?' (2012) 9(3) SAHARA: Journal of Social Aspects of HIV/AIDS 160

Mpelega, L 'Interpretation of lived experiences of transgender people in Gaborone Botswana' (2013) Master of education research essay, University of Botswana

Müller, A Are we doing alright? Realities of violence, mental health, and access to healthcare related to sexual orientation and gender identity and expression in East and Southern Africa: Research report based on a community-led study in nine countries (2019)

Murray, S 'Africa: Sub-saharan, pre-independence' in Summers, CJ (eds) GLBTQ: An encyclopedia of gay, lesbian, bisexual, transgender and queer culture (Emerald Group Publishing Limited 2004)

Ngwena, C What is Africanness? Contesting nativism in race, culture and sexuality (PULP 2018)

Nyanzi, S 'Unpacking the [govern]mentality of African sexualities' in Tamale, S (ed) African sexualities: A reader (Fahamu Books and Pambazuka Press 2011)

Reed, G, Drescher, J, Krueger, R, Atalla, E, Cochran, S, First, M, Cohen-Kettenis, P, Arango-de Montis, I, Parish, S, Cottler, P, Briken, P \& Saxena, S 'Disorders related to sexuality and gender identity in the ICD-11: Revising the ICD-10 classification based on current scientific evidence, best clinical practices, and human rights conditions' (2017) 16 World Psychiatry Journal 209

Report of the Independent Expert on protection against violence and discrimination based on sexual orientation and gender identity on the promotion and protection of all human rights, civil, political, economic, social, cultural rights, including the right to development A/HRC/35/36 2017

Report of the Independent Expert on protection against violence and discrimination based on sexual orientation and gender identity Resolution A/HRC/41/45 2019

Report of the UN High Commissioner for Human Rights on discrimination and violence based on sexual orientation and gender identity A/HRC/29/23 2015

Rubin, G 'Thinking sex: Notes for a radical theory of the politics of sexuality' in Aggleton, P and Parker, R (eds) Culture, society and sexuality (Routledge 2006)

Serano, J Whipping girl: A transsexual woman on sexism and the scapegoating of femininity (Seal Press 2007)

Southern Africa Litigation Centre Laws and policies affecting transgender persons in Southern Africa (Southern Africa Litigation Centre 2016)

Theilen, J 'Depathologisation of transgenderism and international human rights law' (2014) 14(2) Human Rights Law Review 327

UN Office of the High Commissioner for Human Rights, Joint UN statement on ending violence and discrimination against lesbian, gay, bisexual, transgender and intersex people (2015)

Viljoen, F 'Botswana court ruling is a ray of hope for LGBT people across Africa' (2019) http://theconversation.com/botswana-court-ruling-is-a-ray-of-hope-for-lgbt-people -across-africa-118713 (accessed 2 September 2019) 
170 Kutlwano Pearl Magashula

Winter, S, Settle, E, Kevan, W, Reisner, S, Cabral, M, Knudson, G \& Baral, S 'Synergies in health and human rights: A call to action to improve transgender health' (2016) 388 The Lancet 318.

World Bank Group Identification for development (ID4D) country diagnostic: Botswana (World Bank Group 2016)

World Health Organization Sexual Health, Human Rights and the Law (World Health Organization (2015) 